\title{
Cross-visiting Behaviour of Online Consumers Across Retailers' and Comparison Sites, a Macro-Study
}

\author{
Sahar Karimi ${ }^{1}$ (D) \\ Published online: 13 December 2019 \\ (C) The Author(s) 2019
}

\begin{abstract}
Extant academic research provides a comprehensive view of online consumer behaviour on a single website, paying less attention to the integrated environment in which websites operate. Retailers' products, however, are not only available on their own website, but also through other connected channels such as comparison sites. Our limited knowledge of consumers' integrated behaviour across the entire market poses difficulties to design effective online strategies. At the same time, practitioners have mainly focused on website performance measures, ignoring the reasons behind the behaviour of consumers. A deeper understanding of consumers who visit different websites or, cross-visit, can inform successful online channel strategies. This macrolevel study aims to bridge this gap by investigating how the usage behaviour on retailers' websites and comparison sites influences each other, using large-scale industry-based data. A new measure of 'cross-visiting' behaviour is introduced and examined.
\end{abstract}

Keywords Cross-visiting $\cdot$ Comparison sites $\cdot$ Search behaviour $\cdot$ E-services $\cdot$ Usage behaviour

\section{Introduction}

Over the past decades, the Internet has immensely transformed the retailing industry. It has not only altered the level of competition and market structure, but also created opportunities for emergence of new forms of intermediaries. For instance, online intermediaries such as comparison sites have become a fundamental part of online retailing scene (Armstrong and Zhou 2011), with 85\% adoption rate in the UK (Hanson et al. 2017). Comparison sites are vertical search engines that offer helpful information to consumers by conveniently aggregating products from various retailers in one place (Laffey and Gandy 2009). They affect the behaviour of consumers by changing their search and decision-making processes (Bodur et al. 2015) and influencing their switching behaviour (McDonald and Wren 2012). Therefore, consumers who visit comparison sites may behave differently on retailers' channels. Understanding their holistic and interrelated behaviour where retailers' websites and comparison sites cohabit is essential.

Sahar Karimi

Sahar.Karimi@liverpool.ac.uk

1 University of Liverpool Management School, University of Liverpool, Chatham Street, Liverpool L69 7ZH, UK
Consumers search for and compare alternatives across different websites (Balasubramanian et al. 2005; Chatterjee 2010; Wang et al. 2018) and move from one to another for a single purchase (Choudhury and Karahanna 2008). During their journey, they may visit both retailers' website and comparison sites; this translates into cross-visiting behaviour between the two. Their behaviour on one website is influenced by previously visited ones (Park and Fader 2004). However, consumers' holistic behaviour and the way they search and move across different websites has received little attention (Wang et al. 2018). On one hand, studies of comparison sites have focused on their role as standalone decision support systems that facilitate consumer decision-making, even though these websites do not perform in isolation. On the other hand, extant literature on online channels has remained focused on the delivery of products/services through either the retailers' or intermediaries' channel (See Fig. 1a). But consumers do not make a 'monolithic decision' between the two; they may simultaneously interact with both retailers and online intermediaries, in other words, cross-visit (See Fig. 1b).

Retailing industry suffers from the same deficiencies. Despite their increasing reliance on Web analytics to collect visitors' behavioural data, their measurement metrics are concerned with behaviour on one website or, at best, compare the reach from different sites, rather than capitalizing on cross-visiting behaviour. Moreover, these metrics are treated as standalone granular 
Fig. 1 Two approaches to consumers' online channel usage: (a) abiding channel behaviour (b) dynamic cross-channel behaviour

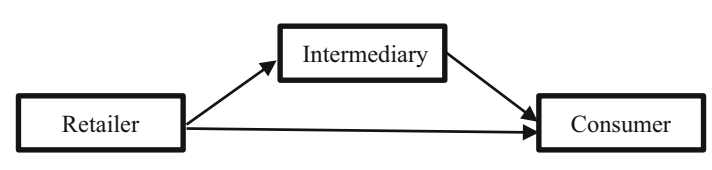

(a)

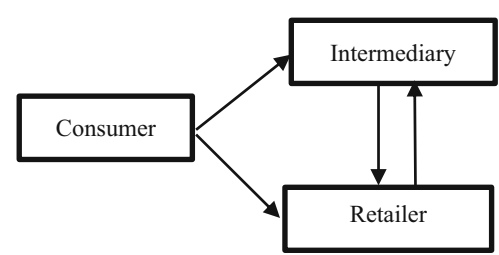

(b) performance measures that their relation to consequent behavioural measures has remained unclear. Hence, these measurement systems are not used to their potential and for strategic purposes (Järvinen and Karjaluoto 2015).

This research explores how consumers actively engage with this entangled network of retailers and intermediaries and, through their behaviour, shape cross-channel interrelations. It addresses a number of important frontiers in Information Systems that concern academics and practitioners. At first, it introduces a new measure of cross-visiting that captures entangled interactions of consumers on online platforms and complements conventional measures (Aydin and Perdahci 2019). Then, it draws on a large-scale tracking data of million users across different websites to analyze consumers' holistic behaviour. Examining real-life logs of user behaviour is increasingly important, as it captures the actual usage rather than users' intension (Wang et al. 2010) and provides valuable insight into online behaviour (Wang et al. 2012, 2015). In addition, actual usage does not rely on participant's self-reported behaviour. This is advantageous because usage data retrieved from system logs is not necessarily correlated with subjective self-reported usage (Albashrawi et al. 2019). In addition, measuring the actual behaviour of consumers can create business insights by offering valuable usage-based segmentation (Trivedi et al. 2018).

Finally, the importance of cross-visiting is not confined to its occurrence but to its ability to explain consequent behaviour. This research examines the relation between cross-visiting and other important behavioural measures. It is motivated by retailers' profound reliance on tracking data from Web analytics, while such measures are not yet connected to other performance/ behavioural measures. Therefore, two phenomena associated with consumer cross-visiting behaviour are tested. First, crossvisiting with comparison sites may affect the extent of search behaviour on retailers' website. That is because comparison sites encourage asymmetric behaviour across different retailers (Iyer and Pazgal 2003) and alter consumers' information search (Breuer et al. 2011). Second, use of retailers' e-services could relate to the portion of switching-related activities, i.e. crossvisiting with comparison sites. Customers who tend to be frequent users of retailers' services are less likely to actively research competitors on comparison sites (Keaveney and Parthasarathy 2001). E-loyalty is an important measure of success in online channels (Chen et al. 2015).
This research contributes to the literature by examining the cross-visiting behaviour of consumers between comparison sites and retailers' websites. Findings inform managers on how to devise successful segmentation and distribution strategies across their online network. In addition, this research bridges the gap between academic research and managerial practices by using industry-based measures to test theoretically important questions. The objectives of this paper are as follows:

- First, a measurement framework is introduced to examine various aspects of consumer 'within-site' and 'cross-visiting' behaviour.

- Second, the relation between cross-visiting and search behaviour on retailers' website is examined.

- Third, the relation between e-service usage behaviour and the extent of switching-related activities is tested.

To do so, the interactions of consumers with all the retailers and main comparison sites are analyzed in two UK markets: mobile network providers and banking sector. These two sectors are of particular interest to this research, because comparison sites have introduced significant changes to their consumers' search and switching behaviour. Whereas they highly depend on long term and continuous use of their services and consumer switching has a shattering effect on their bottom lines (Keaveney and Parthasarathy 2001).

\section{Research Background}

\subsection{Consumers' Behaviour across the Network}

Researchers have long emphasized the importance of understanding consumer cross-channel behaviour (Montoya-Weiss et al. 2003; Xiao et al. 2019), focusing mainly on retailers' online and offline channels (e.g. Dholakia et al. 2005; Konuș et al. 2008). They have identified consumer preferences and determinants of online channel use (Neslin et al. 2006; Ansari et al. 2008; Montoya-Weiss et al. 2003). But only a handful of studies have recognized the role of online intermediaries that operate alongside retailers within the market (Nicolau 2013; Magnini and Karande 2011; Su 2007), with no attention being paid to crosschannel behaviour between retailers' and intermediaries' 
websites. It is consumers' dynamic interactions with both channels that shape their overall purchase behaviour (Karimi et al. 2010), making it crucial for firms to understand cross-channel activities.

At the same time, online search behaviour has become more and more complex. Consumers are able to access product information from variety of sources. They visit different retailers and perform cross-site search activities (Su 2007) to reach a decision. Complex product purchases, in particular, involve collecting information from diverse range of sources and consulting impartial information from online intermediaries (Urban et al. 2000). Therefore, consumers move across different retailers' sites (Balasubramanian et al. 2005; Chatterjee 2010) and comparison sites (Magnini and Karande 2011; Nicolau 2013) to maximize their purchase utility. This leads to high degree of complex crossvisiting behaviour on the network.

To provide a comprehensive understanding of consumers' search behaviour across the market, the relation between within-site and cross-visiting behaviour should be explored (Fig. 2). This study develops the concept of cross-visiting by drawing on measures of behaviour in a single website (Montgomery et al. 2004; Park and Fader 2004; Johnson et al. 2004) and industry-based metrics. A measurement framework that is managerially relevant and can capture and examine the behaviour in a more holistic manner is introduced.

\subsubsection{Within-Site Behaviour}

Behaviour within a website is related to consumers' use of that website. It can be associated with the level of adoption and usage intensity (Klein 1998; Sproule and Archer 2000). Level of adoption shows the portion of the population that uses a particular website, channel or service. It captures the total number of consumers, as unique visitors (UV), who have used the Internet to reach retailers or comparison sites. While usage intensity shows the depth of online activities that consumers engage with. It is associated with the amount of information that is retrieved and evaluated on a website (Klein 1998; Rozic-Hristovski et al. 2002). Usage intensity or engagement in an online environment has been previously measured by the duration of visit (Ip and Wagner 2008; Trivedi et al. 2018) and number of pages visited
(Rozic-Hristovski et al. 2002). These measures capture the behaviour of consumers within one specific website and are used in this research.

Usage behaviour on retailers' website only captures a portion of overall search behaviour. Many consumers choose to perform their search activities on comparison sites and have a relatively high usage intensity within these websites. This is because comparison sites enhance the utility of online purchase by providing helpful aggregated information in one place. They simplify consumer search and evaluation behaviour, reduce confusion, and increase decision satisfaction (Barnes and Hinton 2007; Laffey and Gandy 2009). Therefore, one might expect their adoption and usage intensity to be, if not higher, comparable to retailers' websites.

\subsubsection{Cross-Visiting Behaviour}

Online consumers disaggregate their search and purchase activities over available channels and move from one to another (Choudhury and Karahanna 2008; Tih and Ennis 2006), shaping a complex behaviour across different websites. They might visit retailers' website and/or comparison sites to evaluate and purchase products. Their behaviour across the network of multiple websites includes the new concept of 'crossvisiting'. Cross-visiting behaviour occurs when a consumer visits two websites or online channels in one journey.

Studies that account for consumer cross-visiting behaviour are scarce (Chatterjee 2010). However, analyzing the behaviour on one channel, and in isolation, can lead to incorrect conclusions (Anderl et al. 2016). When consumers interact with multiple websites, their behaviour on a particular site is influenced by their activities on previously visited ones (Park and Fader 2004). Cross-visiting retailers' website and comparison sites in one journey means that their behaviour is influenced by the two. Thus, recognizing cross-visiting behaviour is essential to a realistic understanding of consumers. Such knowledge has important implications for those offering their product and services on both channels. This can affect marketing strategies of competing firms (Mcdonald and Wren 2012), provide some retailers with a higher visibility and enhanced traffic, and influence performance ( $\mathrm{Su}$ 2007). In addition, cross-visiting with
Fig. 2 Consumer behaviour across retailers' and comparison websites

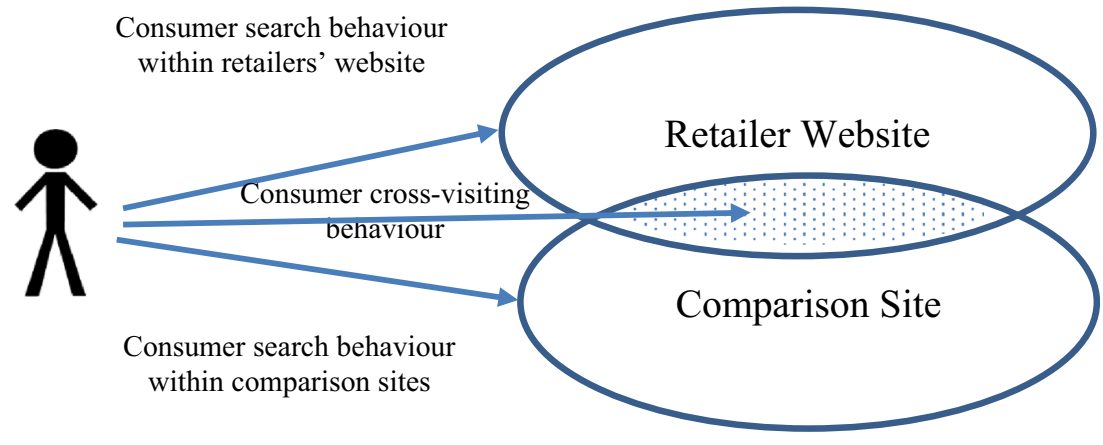


comparison sites is an indicator of the size of price sensitive switchers in the market that can influence targeting strategies of retailers (Iyer and Pazgal 2003; Koçaş and Bohlmann 2008).

\subsection{Cross-Visiting and Behaviour on Retailers' Website}

Despite the dependency of behaviour on different websites, the relation between cross-visiting and within-site behaviour has not been previously examined. It is already known that comparison sites alter the way consumers interact with retailers (Armstrong and Zhou 2011). By allowing users to compare prices and product information (Anderl et al. 2016), they influence the information search behaviour (Peterson and Merino 2003) and purchase decisions (Haubl and Trifts 2000). The distribution of online activities, i.e. search, over different retailers is also transformed due to the way consumers interact with these websites (Brynjolfsson et al. 2010). Therefore, cross-visiting with comparison sites may alter the behaviour on retailers' online channel.

More specifically, comparison sites facilitate information search and evaluation, and simplify consumer problem-solving behaviour (Anderson and Anderson 2002; Sarkar et al. 1995). By providing effective information, they can reduce the time and effort allocated to search activities (Eighmey and McCord 1998; Klein 1998). In other words, use of comparison sites can simplify decision making and reduce cognitive effort on retailers' website. When consumers visit comparison sites, a link takes them directly to the product page on retailers' site (Breuer et al. 2011) minimizing their navigation. Therefore, use of comparison sites affects the usage intensity on retailers' website in terms of number of pages visited and time spent. This study examines whether a higher level of cross-visiting between a retailer and comparison sites will result in lower usage intensity (less time spent and fewer number of pages visited) on the retailer.

H1a: The level of cross-visiting with comparison sites is negatively related to the duration of visit on retailers' website.

$\mathrm{H} 2 \mathrm{~b}$ : The level of cross-visiting with comparison sites is negatively related to the number of pages visited on retailers' website.

\subsection{E-Service Usage Behaviour and the Extend of Switching-Related Activities}

The level of involvement with e-services determines consumer switching intentions (Dabholkar and Walls 1999) and can lead to different price comparison behaviour. Higher usage creates psychological attachments which can affect retention (Xiao et al. 2019), hence switching intentions. Study of Keaveney and Parthasarathy (2001) is one of the very few that have investigated the relationship between level of service usage and switching behaviour. Their findings show that more intensive use of services will result in lower switching behaviour. This is because intensive use of retailers' services leads to higher satisfaction with the service, and consumer satisfaction with the service determines their behavioural intentions and loyalty (Dai and Salam 2019; Wang et al. 2004). Higher service usage is associated with lower service failure and occurrences of disconfirmation of service quality. Consumers compare the quality of a service with a norm or standard expectation they have from the service. A frequent service usage behaviour provides accurate and realistic performance expectations (Keaveney and Parthasarathy 2001) that lead to loyalty or lower switching intentions (Anderson and Sullivan 1993). In addition, frequent service usage leads to consumer learning that is an important predictor of switching intension in online environment (Hoch and Deighton 1989). When consumers become familiar with an online service, they are less likely to switch to competitors. Use of e-services, therefore, affects the switching intentions of consumers.

Switching intentions on the internet are indicated by crossvisiting and search activities on other retailers and comparison sites (Srinivasan et al. 2002; Koçaş and Bohlmann 2008). Unlike switchers, loyal customers do not perform comparison across retailers (McDonald and Wren 2012) and do not use comparison sites (Iyer and Pazgal 2003). It is expected that more intensive use of a retailers' e-services by its consumers would increase the share of satisfied loyal customers compared to switchers. Having a lower share of switchers is associated with less switchingrelated activities on retailers' online channel such as use of comparison sites. Therefore, those retailers whose e-services are used more intensively may have a smaller share of switchers, hence, less switching-related activities on their online channel, i.e. crossvisiting with comparison sites. E-service usage can be defined in terms of its frequency and duration (Ram and Jung 1990; Keaveney and Parthasarathy 2001). The extent of switchingrelated activities on each retailer is defined as the portion of activities on retailers' website that contain cross-visiting with comparison sites.

H2a: Frequency of service usage on a retailers' website is negatively related to the extent of switching-related activities.

H2b: Duration of service usage, on a retailers' website is negatively related to the extent of switching-related activities.

\subsection{Retailers' Size and the Extent of Switching-Related Activities}

The size of a retailer may also be related to the extent of switching-related activities performed by its customers. The number of loyal customers is highly correlated with the firm's size (McDonald and Wren 2012). Larger and more well- 
known firms focus mainly on loyal customers and charge higher prices. Smaller firms that have fewer loyal customers are more inclined to attract switchers by offering promotions or additional benefits compared with larger ones (Koçaș and Bohlmann 2008). Loyal customers have a high degree of loyalty and stay with the firm. They do not search competitors' products (McDonald and Wren 2012) or use comparison sites (Iyer and Pazgal 2003). In fact, loyalty towards an online retailer is indicated by the absence of search across other retailers (Srinivasan et al. 2002; Koçaş and Bohlmann 2008). Switchers, who are price sensitive, are not loyal to any retailer and switch to the one with the best offer. They use comparison sites to compare and locate the best option (Iyer and Pazgal 2003). Therefore, the extent of switching-related activities on retailers' website is expected to be higher for smaller retailers compared to larger ones as they attract switchers.

H3: A retailer's size is negatively related to the extent of switching-related activities on its online channel.

\section{Research Method}

\subsection{Data Collection}

For the purpose of this research and in order to analyze the actual behaviour of consumers who visit retailers' and comparison sites, data was collected from an online panel data provider that measures the behaviour of consumers across the entire market. Most academic research on multi-channel behaviour has been based on surveys or secondary data. Measuring the actual channel usage behaviour is, however, encouraged (Konuş et al. 2008). Actual usage data collected through tracking methods allows researchers to form an accurate understanding of online behaviour. This data goes beyond the purchase activity (Van den Poel and Buckinx 2005) and provides detailed analysis of all interactions with retailers. Tracking data can reveal the actual behaviour over time, eliminating the limitations of laboratory experiments. In addition, it captures the behaviour as it occurs and does not rely on selfreported behaviour. It also has the advantages of selfadministrated results, such as eliminating the effect of the researcher, social desirability and time pressure (Kiesler and Sproull 1986; Schwarz et al. 1991). Additionally, this data is more tangible to marketing practitioners, hence enriches the managerial implications of research findings (Houston 2004).

Tracking data has been previously used to measure the behaviour in one particular website (e.g. Montgomery et al. 2004; Moe 2006). However, analysis of data for a single website captures an incomplete view of consumer behaviour; whereas collective behaviour across different websites can depict a more holistic picture (Park and Fader 2004). Online panels offer behavioural data by recording the entire online activities of a very large sample of individuals. They provide interesting insights into consumers' collective behaviour on different websites (Bucklin et al. 2002). In this research, data from an online panel data provider, comScore, that tracks the entire behaviour of millions of users was collected. This data source has been used in prior research (e.g. Danaher 2007; Johnson et al. 2003; Koçaş and Bohlmann 2008; Wang et al. 2018) and includes rich micro-level data on all retailers (Koçaş and Bohlmann 2008). This advanced real consumer data could therefore be used to understand the behaviour across multiple retailers (Hinz et al. 2011; Van den Poel and Buckinx 2005).

Within- and cross-website behaviour can be measured using online panel data (Karimi 2013). To test the hypotheses, two categories of behavioural data were used: a) consumer within-site behaviour in terms of channel adoption, usage intensity, frequency of using e-services and b) consumer crossvisiting behaviour across multiple websites. The data is based on a sample of over 2 million unique visitors. Three-month behaviour of UK consumers on all retailers in the selected sectors was collected for two consecutive years.

\subsection{Measurements}

Common measures of within-site usage behaviour which are widely used in industry and academic research were adopted. Due to the absence of a measurement that can capture the cross-visiting behaviour, new measurements were developed. Inclusion of both within-site and cross-visiting measures enables a much more detailed evaluation of online behaviour.

Data was collected to measure the online channel adoption, usage intensity, level of cross-visiting, and extent of switching-related activities. In order to examine the adoption of online channels, two most common measures of online usage, number of unique visitors (Tarafdar and Zhang 2005) and reach (Li and Wang 2011), were collected. Number of unique visitors (UV) indicates the extent to which a channel or website is accessed by consumers. Reach measures the portion of the population using a channel or a website, which is a direct measure of channel adoption by consumers. Duration and number of pages visited (Ip and Wagner 2008; Rozic-Hristovski et al. 2002) for the entire website as well as product-related pages were examined to assess the intensity of website usage. To test H1, data from the product sub-domain was used in order to eliminate those consumers who visit the website for any reason other than product search, i.e. use of services. Duration and frequency of using online services (Keaveney and Parthasarathy 2001) were also collected for the service sub-domains. Frequency of service use was defined as the number of times that customers engaged with online services and was operationalized as the number of repeated visits. Duration of service usage was measured by the interaction time with e-services. In addition to above within- 
site measures, this panel provides data on the number of consumers who visit both of any two selected websites. This is termed cross-visiting data. This measurement is of particular interest to this research as it indicates the number of consumers who visit both retailers and comparison sites during their information search, and therefore perform cross-visiting in the market. Cross-visiting data between each retailer and comparison sites was gathered. Comparison sites in the financial sector are not limited to banking products; therefore, collected data was limited to the relevant sub-domains of comparison sites that contained banking products only. The extent of switching-related activities was also collected. This measure indicates the portion of activities on retailers' website that is linked to cross-visiting with comparison sites. Similarly, this data was measured for the sub-domain of comparison sites that offers relevant products. Table 1 summarizes all the variables used in this study.

\subsection{Selected Sectors: Banking and Mobile Network Providers}

Two sectors of banking and mobile network providers were selected as cross-channel behaviour is an important characteristic of consumers in these markets (Montoya-Weiss et al. 2003). Additionally, they are at the forefront of online distribution and show interesting potentials for development.

The banking sector has undergone significant changes in the way that consumers interact with banks. Online banking services have transformed the banking industry through innovation and improved performance (Boateng et al. 2016). Researchers have paid particular attention to online and mobile banking in this sector. However, a report by Retail Banking Quarterly, found that UK consumers are conducting more and more search activities for banking products (Greenlight 2014). This in fact has opened a new chapter for this sector, illustrating the use of online channel for information search in addition to online banking services. Moreover, comparison sites have accelerated the growth of online search for banking products. The second sector selected in this research is mobile network industry, which is an important service sector. The mobile network industry has received a major boost from the advancements and growing trend of smart device usage. Providers are competing intensely for a greater market share. The rapid rate of change in the UK market, in addition to the complexity of networks, tariffs and contracts, makes comparison between different networks and selection of the best value tariff difficult. Therefore, consumers use comparison sites to evaluate different alternatives.

To test the hypotheses, main market players that had over $5 \%$ market share (eight banks and six network providers) as well as the two main comparison sites in each sector were selected for further analysis. Similar studies of online retailers have examined comparable number of firms (e.g. Xing et al. 2006; Koçaș and Bohlmann 2008).

\section{Results and Discussion}

To understand the behaviour of consumers across retailers' website and comparison sites, first, a complete picture of their interactions with both channels is presented. Then, the way comparison sites influence behaviour by directing consumers to certain retailers is illustrated; and finally, research hypotheses are tested.

\subsection{Overall Online Channel Statistics}

Table 2 illustrates the aggregated data for banking sector and network providers. It includes main market players (eight banks and six network providers) and the two main comparison sites in each sector. It is clear that a large number of consumers visit retailers' websites in these two sectors. During the observation period, $39.2 \%$ and $30.2 \%$ of population interacted with main banks and mobile network providers, respectively. As expected, comparison sites are used by a considerable portion of UK consumers, $11 \%$ to $22 \%$, that highlights their importance in the market. The usage intensity of these websites such as average usage duration and number

Table 1 Measurement metrics for consumer behaviour on online channels

\begin{tabular}{|c|c|}
\hline Measurement & Definition \\
\hline Number of unique visitors (UV) & $\begin{array}{l}\text { The estimated number of different individuals that visited a website, a sector, or a } \\
\text { channel during the reporting period }\end{array}$ \\
\hline Reach & The portion of the population visiting a particular website or sector \\
\hline Usage duration & The average length of time spent on the website/e-services \\
\hline Number of pages visited & The average number of pages visited by visitors \\
\hline Frequency of use & The average number of visits to a website/sub-domain per individual \\
\hline Cross-visiting between two websites & The number of unique visitors who visited any two selected websites/sub-domain \\
\hline Extend of switching-related activities & $\begin{array}{l}\text { The portion of activities on retailers' website that illustrates switching intentions } \\
\text { by containing cross-visiting with comparison sites }\end{array}$ \\
\hline
\end{tabular}


Table 2 Use of retailers' website and comparison sites

\begin{tabular}{|c|c|c|c|c|c|}
\hline \multirow[b]{2}{*}{ Website } & \multicolumn{2}{|l|}{ Adoption } & \multicolumn{2}{|l|}{ Usage intensity } & \multirow{2}{*}{$\begin{array}{l}\text { Cross-visiting } \\
\text { Average cross-visiting } \\
\text { between comparison } \\
\text { sites and each retailer in the sector }\end{array}$} \\
\hline & $\begin{array}{l}\text { Number of } \\
\text { UV }\end{array}$ & $\begin{array}{l}\text { Overall Reach \% } \\
\text { (Reach in their sector \%) }\end{array}$ & $\begin{array}{l}\text { Usage duration } \\
\text { (min) }\end{array}$ & $\begin{array}{l}\text { Number of pages } \\
\text { visited }\end{array}$ & \\
\hline Eight banks & $16,367,000$ & 39.2 & 2.95 & 4.96 & N/A \\
\hline Six Network providers & $12,886,000$ & 30.2 & 4.98 & 8.65 & N/A \\
\hline Comparison site A -banking sector & $3,600,000$ & $8.7(22)$ & 3.7 & 3.4 & 597,600 \\
\hline Comparison site B - banking sector & $2,700,000$ & $7.1(16)$ & 5.0 & 6.2 & 325,350 \\
\hline Comparison site $\mathrm{C}$-mobile providers & $2,100,000$ & $5.3(16)$ & 5.0 & 10.3 & 432,600 \\
\hline Comparison site D - mobile providers & $1,400,000$ & $2.3(11)$ & 3.3 & 5.3 & 222,600 \\
\hline
\end{tabular}

of pages visited is comparable to retailers' websites, showing their influence on consumer decision-making. In addition, a noticeable number of consumers visit both comparison sites and retailers' website, as represented by average cross-visiting between the two.

\subsection{Impact of Comparison Sites on Consumer Search Behaviour}

In order to establish the impact of comparison sites on consumers' decision to visit a retailer, a clustering analysis of cross-visiting behaviour on multiple websites was performed. This analysis categorizes websites based on similar crossvisiting behaviour with other websites. Hence, visitors of websites in one cluster show similar behaviour in terms of visiting other websites. Cross-visiting between any two retailers or a retailer and a comparison site ranges from $2 \%$ to $30 \%$. Clustering analysis as a classification tool makes no prior assumption about important differences within a population (Punj and Stewart 1983), and therefore is a suitable choice for grouping macro-level data. The preliminary clusters were identified by a hierarchical method of Ward's minimum variance. The dendrogram (Fig. 3) shows that the two comparison sites are very similar, while all other retailers tend to be individually positioned in separate clusters, suggesting a level of dissimilarity. This finding indicates that visitors of comparison sites exhibit similar cross-visiting behaviour and visit the same retailers. That is, these sites influence consumers' behaviour by directing them to certain websites and shaping the distribution of customers in the market.

\subsection{Cross-Visiting with Comparison Sites and Usage Behaviour}

To test the impact of cross-visiting with comparison sites on two usage intensity variables, usage duration and number of pages visited (H1a and $\mathrm{H} 1 \mathrm{~b})$, multivariate analysis was conducted. The structure of retailers' websites in each sector is very similar; however, there are differences between the two sectors. Sector was used as a control variable to avoid any confounding impact it may have on usage intensity. Tables 3 and 4 show the correlations between variables and the

Dendrogram Using Ward Linkage

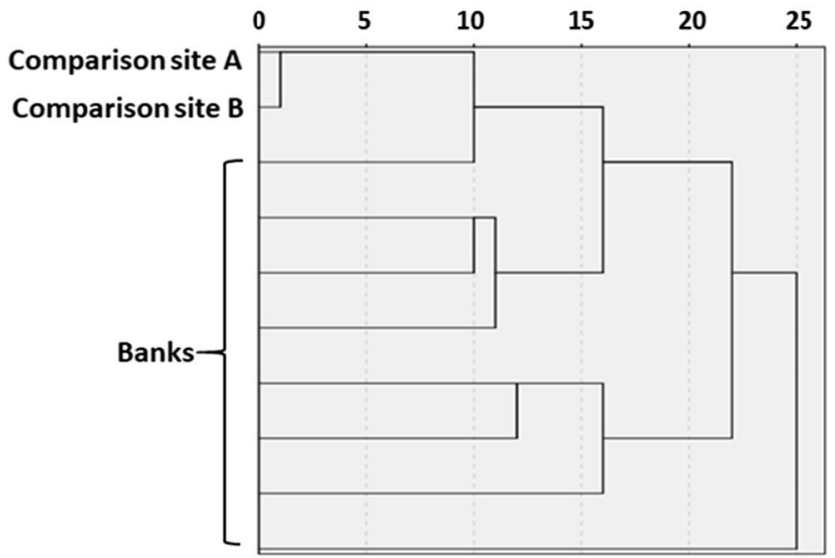

Banking sector

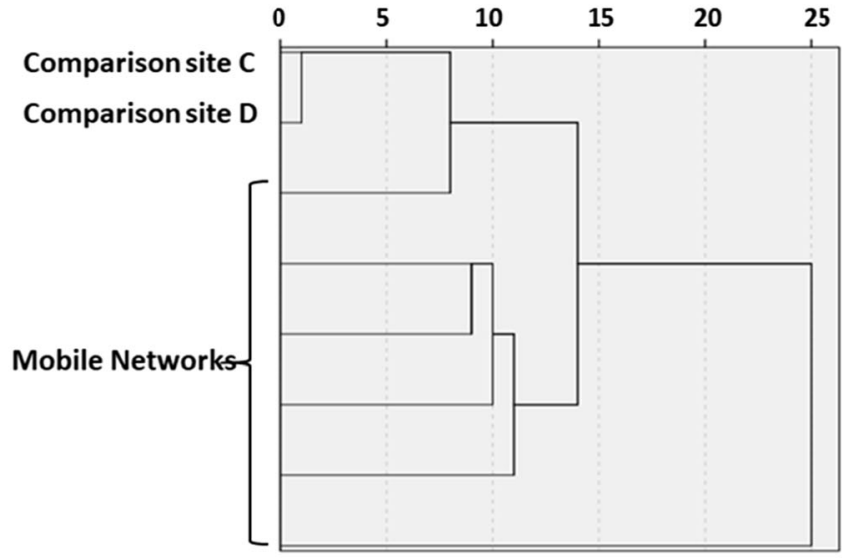

Mobile network sector

Fig. 3 Clustering of retailers' website and comparison sites based on similarity in cross-visiting behaviour across the entire market 
Table 3 Correlations between cross-visiting and website usage behaviour

\begin{tabular}{lll}
\hline & Number of pages visited & Duration of visit \\
\hline Level of Cross-visiting & $.475^{*}$ & $.675^{* *}$ \\
Sector & $-.518^{*}$ & $-.53^{*}$ \\
\hline
\end{tabular}

${ }^{*} p<0.05 ; * * p<0.01$

analysis' results. In contrast to the hypothesized $\mathrm{H} 1 \mathrm{a}$ and $\mathrm{H} 1 \mathrm{~b}$, the level of cross-visiting has a positive effect on the time spend on retailers' website $(\mathrm{F}=6.181, p=.030)$ and the number of pages visited $(\mathrm{F}=5.048 ; p=.046)$. This positive relationship suggests that comparison sites do not reduce the intensity of search behaviour on retailers' websites; but, as the level of cross-visiting increases, retailers enjoy a more indepth evaluation of their offerings.

Prior research has used comScore data to perform regression analysis on the same number of retailers (e.g. Koçaș and Bohlmann 2008). However, due to the limited sample size, I collected data for two consecutive years and treated them as separate observations. Same analysis was conducted on the pooled data that contained a sample of 28 retailers (Table 5). As it can be noticed, the direction of cross-visiting effect on usage intensity remained the same. It must be noted that no effect for the year, as a dummy variable, was found.

Although R square shows a good model fit, due to the nature of this research and number of market players in each industry, this should not be treated as a predictive model. The objective is to test the relations between the independent and dependent variables.

\subsection{The Extent of Switching-Related Activities, Retailer's E-Service Usage Intensity and Size}

To test the impact of retailers' size and e-service usage intensity on switching-related activities ( $\mathrm{H} 2$ and $\mathrm{H} 3$ ), a series of analysis was performed. The extent of switching-related activities for each retailer was calculated as the portion of activities on its website that illustrated switching intentions and involved cross-visiting with comparison sites. Therefore, this measure is independent of retailers' size. Two regression models were run to test $\mathrm{H} 2$ and $\mathrm{H} 3$. First analysis included 14 retailers, with total number of UV (size) and service usage frequency as independent variables and the extent of switching-related activities as the dependent variable. In the second model, the service usage duration was also included, using the two-year pooled data. Tables 6 and 7 show the regression results. To test for a potential difference in switchingrelated activities between the two sectors a t-test was conducted; no significant difference was found $(\mathrm{F}=.900 ; p=.362)$.

Service usage frequency has a significant negative effect on the extent of switching-related activities. $\mathrm{H} 2 \mathrm{a}$ is supported in both models. Those retailers whose services are used more frequently tend to have less switching-related activities on their websites. $\mathrm{H} 2 \mathrm{~b}$ was not supported. The time spent on using online services does not influence switching-related behaviour of consumers. The size of the retailer does not affect the switching-related activities; H3 was not supported. This sample size may be relatively small for excellent prediction level, but it is adequate for a good prediction (Knofczynski and Mundfrom 2008).

\subsection{Nomological Validity}

Usage intensity (duration of visit and number of pages visited) and service usage (frequency and duration of service usage) measures are widely used in extant research. Similar to these measurements, the cross-visiting construct is a clear secondary proxy available on the panel data (Houston 2004) that indicates the exact number of individuals who visit any two selected websites. To verify the construct validity of the extent of switching-related activities, its relation to a broader and a theoretically specified nomological network (Houston 2004) was examined. Nomological validity tests whether a construct performs as expected within its nomological network (Boudreau et al. 2001; McKnight et al. 2002).

Literature suggests that consumer satisfaction is negatively related to switching intentions (Antón et al. 2007; McDougall and Levesque 2000). Additionally, complaint management correlates negatively with switching intention (Keaveney 1995; Colgate and Hedge 2001). Data on consumer satisfaction and complaint management for each of the retailers was collected from industry reports for the sample years. The two sectors were separated for this analysis as data collection methods were not identical. The correlation coefficient was used to examine the suggested nomological links (Houston and Johnson 2000). Results show that a significant negative relationship holds between switching-related activities and
Table 4 Impact of cross-visiting on usage intensity (based on 14 retailers)

\begin{tabular}{lllllll}
\hline Dependent variable & Independent variable & df & MS & F & Sig. & $\mathrm{R}^{2}$ \\
\hline Number of pages visited & Level of cross-visiting & 1 & 37.250 & 5.048 & $.046^{*}$ & .499 \\
& Sector & 1 & 76.336 & 10.344 & $.008^{*}$ & \\
Duration of visit & Level of cross-visiting & 1 & 11.077 & 6.181 & $.030^{*}$ & .396 \\
& Sector & 1 & .200 & .112 & .745 & \\
\hline
\end{tabular}

$* p \leq 0.05$ 
Table 5 Impact of cross-visiting on usage intensity (based on pooled data for two years)

\begin{tabular}{lllllll}
\hline Dependent variable & Independent variable & Df & MS & F & Sig. & $\mathrm{R}^{2}$ \\
\hline Number of pages visited & Level of cross-visiting & 1 & 82.657 & $12.395^{* *}$ & .002 & .453 \\
& Sector & 1 & 21.757 & 3.263 & .083 & \\
Duration of visit & Level of cross-visiting & 1 & 24.959 & $12.319^{* *}$ & .002 & .540 \\
& Sector & 1 & 18.350 & $9.057^{* *}$ & .006 & \\
\hline
\end{tabular}

$* \mathrm{p}<0.05 ; * * \mathrm{p}<0.01$ satisfaction in both sectors (Banking: $\mathrm{r}=-.80, p<0.05$; Mobile Networks: $\mathrm{r}=-.94, p<0.01$ ). Data on complaint management was only available for mobile network providers and showed the percentage of complaints that was resolved. Complaint management was significantly related to switching-related activities $(\mathrm{r}=-.82 ; p<0.05)$. The third nomological link is $\mathrm{H} 2$. As results are consistent with the theory, confidence in the construct validity of this measurement is adequate.

\section{Conclusions and Future Research Direction}

Consumers simultaneously interact with different websites and their behaviour is spread across the network. In order to provide a more holistic understanding of their actions, this research explores their cross-visiting behaviour across the entire network of retailers and comparison sites in two selected sectors. More specifically, it (i) illustrates that use of comparison sites is related to information search behaviour on retailers' website and (ii) reports that frequency of using eservice is associated with the extent of switching-related activities, i.e. cross-visiting with comparison sites.

This study addresses an important frontier in information systems - it introduces new measurements that can capture users' entangled interactions on digital platforms. Such measures are critical in understanding the complexities of online behaviour (Aydin and Perdahci 2019). The proposed measurement framework contributes to the literature by examining the interrelation of consumer behaviour across different online channels. For this purpose, a new concept of cross-visiting is presented. Cross-visiting provides a rounded understanding of consumers in the marketplace that standard measures such as market share and total number of unique visitors are not able to provide. This measurement can, to some extent, predict the direction of consumer journey on the Internet and explain the level of information search effort on retailers' websites. Above all, it is an indicator of retailers' access to potential switchers who are actively searching for a better alternative and use comparison sites; therefore, it provides important and actionable insights to practitioners. Cross-visiting informs the scant literature on underlying mechanisms of information search (Wang et al. 2015) by illustrating users' interrelated search behaviour across the network. It also adds to multichannel research as current performance outcomes are based on limited measures of cross-channel phenomenon (Cao and Li 2015).

Empirical findings highlight the importance of comparison sites to overall information search behaviour. They contribute to the literature by illustrating the relation between consumers' cross-visiting behaviour and the intensity of activities on retailers' website (i.e. duration and number of pages visited). This study shows that comparison sites affect the information search behaviour of consumers by pointing them to certain retailers (see Fig. 3) and directing their evaluation effort. That is, visitors of comparison sites have similar behaviour in terms of visiting other retailers. Retailers that have a higher level of cross-visiting with comparison sites benefit from a more intensive evaluation of their products. Despite the long-term relationship with customers in these two sectors, results show a high rate of usage for comparison sites. This illustrates that a considerable number of consumers are actively looking for the best offer. Moreover, retailers that enjoy a more frequent use of their online services attract a smaller portion of price-sensitive consumers who would use comparison sites, and therefore have less switching-related activities on their websites. Those retailers that their consumers are less involved with their services are more exposed to switching risks. Providing high quality and easy to use e-services and encouraging more frequent service usage can enhance customer loyalty. Also, identification of customers who are more prone to perform comparison activities and have switching
Table 6 Impact of e-service usage and size on switching-related activities (based on 14 retailers)

\begin{tabular}{lllllll}
\hline & \multicolumn{7}{l}{ Switching-related activities } & & \\
\cline { 2 - 7 } Independent variable & $\mathrm{B}$ & $\mathrm{Sig}$ & Std. Error & Beta & $\mathrm{T}$ & $\mathrm{VIF}$ \\
\hline Service usage frequency & -1.586 & $.016^{*}$ & .561 & -.627 & -2.827 & 1.343 \\
Total number of UV & -.001 & .309 & .001 & -.236 & -1.066 & 1.343 \\
\hline
\end{tabular}

$* p<.05 ; \mathrm{R}$ Square: .598 
Table 7 Impact of e-service usage and size on switching-related activities (based on pooled data for two years)

\begin{tabular}{lllllll}
\hline \multicolumn{7}{c}{ Switching-related activities } \\
\cline { 2 - 7 } Independent variable & $\mathrm{B}$ & $\mathrm{Sig}$ & Std. Error & $\mathrm{Beta}$ & $\mathrm{T}$ & $\mathrm{VIF}$ \\
\hline Service usage duration & .208 & .322 & .205 & .145 & 1.012 & 1.068 \\
Service usage frequency & -1.759 & $.000 * *$ & .424 & -.685 & -4.146 & 1.420 \\
Total number of UV & .000 & .440 & .001 & -.126 & -.785 & 1.352 \\
\hline
\end{tabular}

$* * p<.01 ;$ R Square: .539 intentions has interesting implications for retailers. It allows them to locate such customers early on and take measures to prevent them from switching. By offering a usage-based customer segmentation (Trivedi et al. 2018), the findings help managers better understand the cross-channel behaviour of different segments and design effective targeted strategies for each group, for example, price sensitive switchers.

This study examines large-scale observations of consumers' actions, including their entire interactions with different websites. This is valuable as it provides a holistic picture of their behaviour in the market (Wang et al. 2018) and offers in-depth information on continuous usage behaviour which is beyond the purchase activity. This data directly presents the level of cross-visiting behaviour and does not rely on selfreported behaviour. In addition, it has the advantage of being readily understandable by managers and shareholders and 'enhances marketing researchers' abilities to communicate effectively with these groups' (Houston 2004). However, this data is at an aggregate level and the impact of individual differences cannot be measured. Using disaggregated data, future research can provide further insights into individuals' crossvisiting behaviour. In addition, this data identifies customers who cross-visit websites, but the order of visits is not clear. Thus, the study has hypothesized and tested the relations rather than causations. To test the causality and control for the order of actions taken by consumers, future research can use experimental design.

Furthermore, experiments can be conducted to measure other aspects of behaviour such as decision-making strategy or size of the consideration set. The impact of individual characteristics could also be investigated. For example, maximization tendency of consumers, as a personality trait, affects the intensity of search behaviour (Karimi et al. 2015) and could influence the level of cross-visiting activities. The relation between online service usage, switching-related behaviour and use of comparison sites should be explored in other contexts. This could be expanded to include customer satisfaction and retention measures. Additionally, this study has only examined retailers' e-service usage. Future research can investigate service usage across different channels. The portion of cross-visiting with comparison sites is a good indicator of switching-related activities as exhibited by a nomological test. However, it should be noted that well-informed switchers might not perform exhaustive search activities across channels. Other studies that focus on individual consumers can address this issue. Banking and mobile network providers have been selected due to the importance of comparison sites in these sectors, large adoption of their e-services, and importance of long term relationship with customers. However, the results should be tested in other service sectors. Finally, this paper does not aim to develop a prediction equation but to test the statistical significance of relationships. A larger sample of retailers are required for prediction purposes.

Open Access This article is distributed under the terms of the Creative Commons Attribution 4.0 International License (http:// creativecommons.org/licenses/by/4.0/), which permits unrestricted use, distribution, and reproduction in any medium, provided you give appropriate credit to the original author(s) and the source, provide a link to the Creative Commons license, and indicate if changes were made.

\section{References}

Albashrawi, M., Kartal, H., Oztekin, A., \& Motiwalla, L. (2019). Selfreported and computer-recorded experience in mobile banking: A multi-phase path analytic approach. Information Systems Frontiers, 21(4), 773-790.

Anderl, E., Schumann, J. H., \& Kunz, W. (2016). Helping firms reduce complexity in multichannel online data: A new taxonomy-based approach for customer journeys. Journal of Retailing, 92(2), 185203.

Anderson, P., \& Anderson, E. (2002). The new e-commerce intermediaries. MIT Sloan Management Review, 43(4), 53.

Anderson, E. W., \& Sullivan, M. W. (1993). The antecedents and consequences of customer satisfaction for firms. Marketing Science, 12(2), 125-143.

Ansari, A., Mela, C. F., \& Neslin, S. A. (2008). Customer channel migration. Journal of Marketing Research, 45(1), 60-76.

Antón, C., Camarero, C., \& Carrero, M. (2007). The mediating effect of satisfaction on consumers' switching intention. Psychology \& Marketing, 24(6), 511-538.

Armstrong, M., \& Zhou, J. (2011). Paying for prominence. The Economic Journal, 121(556), F368-F395.

Aydin, M. N., \& Perdahci, N. Z. (2019). Dynamic network analysis of online interactive platform. Information Systems Frontiers, 21(2), 229-240.

Balasubramanian, S., Raghunathan, R., \& Mahajan, V. (2005). Consumers in a multichannel environment: Product utility, process utility, and channel choice. Journal of Interactive Marketing, 19(2), $12-30$. 
Barnes, D., \& Hinton, M. (2007). Developing a framework to analyse the roles and relationships of online intermediaries. International Journal of Information Management, 27(2), 63-74.

Boateng, H., Adam, D. R., Okoe, A. F., \& Anning-Dorson, T. (2016). Assessing the determinants of internet banking adoption intentions: A social cognitive theory perspective. Computers in Human Behavior, 65, 468-478.

Bodur, H. O., Klein, N. M., \& Arora, N. (2015). Online price search: Impact of price comparison sites on offline price evaluations. Journal of Retailing, 91(1), 125-139.

Boudreau, M. C., Gefen, D., \& Straub, D. W. (2001). Validation in information systems research: A state-of-the-art assessment. MIS Quarterly, 25, 1-16.

Breuer, R., Brettel, M., \& Engelen, A. (2011). Incorporating long-term effects in determining the effectiveness of different types of online advertising. Marketing Letters, 22(4), 327-340.

Brynjolfsson, E., Dick, A. A., \& Smith, M. D. (2010). A nearly perfect market? QME, 8(1), 1-33.

Bucklin, R. E., Lattin, J. M., Ansari, A., Gupta, S., Bell, D., Coupey, E., Little, J. D., Mela, C., Montgomery, A., \& Steckel, J. (2002). Choice and the internet: From clickstream to research stream. Marketing Letters, 13(3), 245-258.

Cao, L., \& Li, L. (2015). The impact of cross-channel integration on retailers' sales growth. Journal of Retailing, 91(2), 198-216.

Chatterjee, P. (2010). Multiple-channel and cross-channel shopping behavior: Role of consumer shopping orientations. Marketing Intelligence \& Planning, 28(1), 9-24.

Chen, J. V., Yen, D. C., Pornpriphet, W., \& Widjaja, A. E. (2015). Ecommerce web site loyalty: A cross cultural comparison. Information Systems Frontiers, 17(6), 1283-1299.

Choudhury, V., \& Karahanna, E. (2008). The relative advantage of electronic channels: A multidimensional view. MIS Quarterly, 32(1), 179-200.

Colgate, M., \& Hedge, R. (2001). An investigation into the switching process in retail banking services. International Journal of Bank Marketing, 19(5), 201-212.

Dabholkar, P., \& Walls, S. (1999). Service evaluation and switching behavior for experiential services: An empirical test of gender differences within a broader conceptual framework. Journal of Consumer Satisfaction, Dissatisfaction \& Complaining Behavior, 12, 123-137.

Dai, H., \& Salam, A. F. (2019). An empirical assessment of service quality, service consumption experience and relational exchange in electronic mediated environment (EME). Information Systems Frontiers, 1-20.

Danaher, P. J. (2007). Modeling page views across multiple websites with an application to internet reach and frequency prediction. Marketing Science, 26(3), 422-437.

Dholakia, R. R., Zhao, M., \& Dholakia, N. (2005). Multichannel retailing: A case study of early experiences. Journal of Interactive Marketing, 19(2), 63-74.

Eighmey, J., \& McCord, L. (1998). Adding value in the information age: Uses and gratifications of sites on the World Wide Web. Journal of Business Research, 41(3), 187-194.

Greenlight Report. (2014). Retail banking sector report. http://www. greenlightdigital.com/blog/sector-reports-retail-banking/retailbanking-sector-report-december-2014/. Accessed Sept 2017

Hanson, T., Sullivan, S., Fu, E., Abbassian, L., \& Willis, D. (2017). Competition \& Market Authority Report, Digital comparison tools: Consumer research, https://assets.publishing.service.gov.uk/media/ 58e224f5e5274a06b3000099/dcts-consumer-research-final-report. pdf. Accessed Sept 2019

Haubl, G., \& Trifts, V. (2000). Consumer decision making in online shopping environments: The effects of interactive decision aids. Marketing Science, 19(1), 4-21.
Hinz, O., Hann, I. H., \& Spann, M. (2011). Price discrimination in ecommerce? An examination of dynamic pricing in name-your-own price markets. MIS Quarterly, 35(1), 81-98.

Hoch, S. J., \& Deighton, J. (1989). Managing what consumers learn from experience. The Journal of Marketing, 53(2), 1-20.

Houston, M. B. (2004). Assessing the validity of secondary data proxies for marketing constructs. Journal of Business Research, 57(2), 154 161.

Houston, M. B., \& Johnson, S. A. (2000). Buyer-supplier contracts versus joint ventures: Determinants and consequences of transaction structure. Journal of Marketing Research, 37(1), 1-15.

Ip, R. K. F., \& Wagner, C. (2008). Weblogging: A study of social computing and its impact on organizations. Decision Support Systems, 45(2), 242-250.

Iyer, G., \& Pazgal, A. (2003). Internet shopping agents: Virtual colocation and competition. Marketing Science, 22(1), 85-106.

Järvinen, J., \& Karjaluoto, H. (2015). The use of web analytics for digital marketing performance measurement. Industrial Marketing Management, 50, 117-127.

Johnson, E. J., Bellman, S., \& Lohse, G. L. (2003). Cognitive lock-in and the power law of practice. Journal of Marketing, 67(2), 62-75.

Johnson, E. J., Moe, W. W., Fader, P. S., Bellman, S., \& Lohse, G. L. (2004). On the depth and dynamics of online search behavior. Management Science, 50(3), 299-308.

Karimi, S. (2013). A purchase decision-making process model of online consumers and its influential factors cross sector analysis. A Ph.D. Thesis. Manchester Business School. Available: https://scholar. google.co.uk/scholar?hl=en \& as sdt=0\%2C5\&q=A+purchase+ decisionmaking+process+model+of+online+consumers+and+its+ influential+factora+cross+sector+analysis \&btnG $=$

Karimi, S., Papamichail, K. N., \& Holland, C. P. (2010). A model of internet shopper behavior, a cross sector analysis. In Proceedings of the 31th international conference on information systems, Saint Louis, pp. 87.

Karimi, S., Papamichail, K. N., \& Holland, C. P. (2015). The effect of prior knowledge and decision-making style on the online purchase decision-making process: A typology of consumer shopping behaviour. Decision Support Systems, 77, 137-147.

Keaveney, S. M. (1995). Customer switching behavior in service industries: An exploratory study. The Journal of Marketing, 59(2), 71-82.

Keaveney, S. M., \& Parthasarathy, M. (2001). Customer switching behavior in online services: An exploratory study of the role of selected attitudinal, behavioral, and demographic factors. Journal of the Academy of Marketing Science, 29(4), 374-390.

Kiesler, S., \& Sproull, L. S. (1986). Response effects in the electronic survey. Public Opinion Quarterly, 50(3), 402-413.

Klein, L. R. (1998). Evaluating the potential of interactive media through a new lens: Search versus experience goods. Journal of Business Research, 41(3), 195-203.

Knofczynski, G. T., \& Mundfrom, D. (2008). Sample sizes when using multiple linear regression for prediction. Educational and Psychological Measurement, 68(3), 431-442.

Koçaș, C., \& Bohlmann, J. D. (2008). Segmented switchers and retailer pricing strategies. Journal of Marketing, 72(3), 124-142.

Konuş, U., Verhoef, P. C., \& Neslin, S. A. (2008). Multichannel shopper segments and their covariates. Journal of Retailing, 84(4), 398-413.

Laffey, D., \& Gandy, A. (2009). Comparison websites in UK retail financial services. Journal of Financial Services Marketing, 14(2), 173186.

Li, Y., \& Wang, G. (2011). Evaluate the result of consumer to consumer site promotion using correspondence analysis. In Management and service science (MASS), 2011 International conference on (1-4). IEEE.

Magnini, V. P., \& Karande, K. (2011). Understanding consumer services buyers based upon their purchase channel. Journal of Business Research, 64(6), 543-550. 
McDonald, S., \& Wren, C. (2012). Informative brand advertising and pricing strategies in internet markets with heterogeneous consumer search. International Journal of the Economics of Business, 19(1), 103-117.

McDougall, G. H., \& Levesque, T. (2000). Customer satisfaction with services: Putting perceived value into the equation. Journal of Services Marketing, 14(5), 392-410.

McKnight, D. H., Choudhury, V., \& Kacmar, C. (2002). Developing and validating trust measures for e-commerce: An integrative typology. Information Systems Research, 13(3), 334-359.

Moe, W. W. (2006). An empirical two-stage choice model with varying decision rules applied to internet clickstream data. Journal of Marketing Research, 43(4), 680-692.

Montgomery, A. L., Li, S., Srinivasan, K., \& Liechty, J. C. (2004). Modeling online browsing and path analysis using clickstream data. Marketing Science, 23(4), 579-595.

Montoya-Weiss, M. M., Voss, G. B., \& Grewal, D. (2003). Determinants of online channel use and overall satisfaction with a relational, multichannel service provider. Journal of the Academy of Marketing Science, 31(4), 448-458.

Neslin, S. A., Grewal, D., Leghorn, R., Shankar, V., Teerling, M. L., Thomas, J. S., \& Verhoef, P. C. (2006). Challenges and opportunities in multichannel customer management. Journal of Service Research, 9(2), 95-112.

Nicolau, J. L. (2013). Direct versus indirect channels: Differentiated loss aversion in a high-involvement, non-frequently purchased hedonic product. European Journal of Marketing, 47(1/2), 260-278.

Park, Y. H., \& Fader, P. S. (2004). Modeling browsing behavior at multiple websites. Marketing Science, 23(3), 280-303.

Peterson, R. A., \& Merino, M. C. (2003). Consumer information search behavior and the internet. Psychology \& Marketing, 20(2), 99-121.

Punj, G., \& Stewart, D. W. (1983). Cluster analysis in marketing research: Review and suggestions for application. Journal of Marketing Research, 20(2), 134-148.

Ram, S., \& Jung, H. S. (1990). The conceptualization and measurement of product usage. Journal of the Academy of Marketing Science, 18(1), 67-76.

Rozic-Hristovski, A., Hristovski, D., \& Todorovski, L. (2002). Users' information-seeking behavior on a medical library website. Journal-Medical Library Association, 90, 210-217.

Sarkar, M. B., Butler, B., \& Steinfield, C. (1995). Intermediaries and cybermediaries: A continuing role for mediating players in the electronic marketplace. Journal of Computer-Mediated Communication, 1(3), 1-14.

Schwarz, N., Strack, F., Hippler, H. J., \& Bishop, G. (1991). The impact of administration mode on response effects in survey measurement. Applied Cognitive Psychology, 5(3), 193-212.

Sproule, S., \& Archer, N. (2000). A buyer behaviour framework for the development and design of software agents in e-commerce. Internet Research, 10(5), 396-405.

Srinivasan, S. S., Anderson, R., \& Ponnavolu, K. (2002). Customer loyalty in e-commerce: An exploration of its antecedents and consequences. Journal of Retailing, 78(1), 41-50.

$\mathrm{Su}, \mathrm{B}$. C. (2007). Consumer e-tailer choice strategies at on-line shopping comparison sites. International Journal of Electronic Commerce, 11(3), 135-159.
Tarafdar, M., \& Zhang, J. (2005). Analysis of critical website characteristics: A cross-category study of successful websites. Journal of Computer Information Systems, 46(2), 14-24.

Tih, S., \& Ennis, S. (2006). Cross-industry analysis of consumer assessments of internet retailers' service performances. International Journal of Retail \& Distribution Management, 34(4/5), 290-307.

Trivedi, N., Asamoah, D. A., \& Doran, D. (2018). Keep the conversations going: Engagement-based customer segmentation on online social service platforms. Information Systems Frontiers, 20(2), 239-257.

Urban, G. L., Sultan, F., \& Qualls, W. J. (2000). Placing trust at the center of your internet strategy. MIT Sloan Management Review, 42(1), 39.

Van den Poel, D., \& Buckinx, W. (2005). Predicting online-purchasing behaviour. European Journal of Operational Research, 166(2), 557-575.

Wang, Y., Lo, H. P., \& Yang, Y. (2004). An integrated framework for service quality, customer value, satisfaction: Evidence from China's telecommunication industry. Information Systems Frontiers, 6(4), $325-340$.

Wang, J., Xiao, N., \& Rao, H. R. (2010). Drivers of information security search behavior: An investigation of network attacks and vulnerability disclosures. ACM Transactions on Management Information Systems (TMIS), 1(1), 3.

Wang, J., Xiao, N., \& Rao, H. R. (2012). An exploration of risk information search via a search engine: Queries and clicks in healthcare and information security. Decision Support Systems, 52(2), 395-405.

Wang, J., Xiao, N., \& Rao, H. R. (2015). Research note - An exploration of risk characteristics of information security threats and related public information search behavior. Information Systems Research, 26(3), 619-633.

Wang, J., Yang, Z., \& Brocato, E. D. (2018). An investigation into the antecedents of prepurchase online search. Information \& Management, 55(3), 285-293.

Xiao, L., Mi, C., Zhang, Y., \& Ma, J. (2019). Examining consumers' behavioral intention in $\mathrm{O} 2 \mathrm{O}$ commerce from a relational perspective: An exploratory study. Information Systems Frontiers, 21(5), $1045-1068$.

Xing, X., Yang, Z., \& Tang, F. F. (2006). A comparison of time-varying online price and price dispersion between multichannel and dotcom DVD retailers. Journal of Interactive Marketing, 20(2), 3-20.

Publisher's Note Springer Nature remains neutral with regard to jurisdictional claims in published maps and institutional affiliations.

Sahar Karimi is an Assistant Professor of Digital Marketing at the University of Liverpool Management School with focus on digital consumer research. She completed her PhD in Alliance Manchester Business School. She holds an MSc in ICT Management and a BEng in Computer Engineering. Her research interests are in digital consumer behaviour, analysis and modelling of decision processes, information search behaviour, online reviews, usage and impact of smart mobile/wearable devices. Her work has appeared in a number of journals, including Journal of Business Research, Decision Support Systems and Computers in Human Behavior, among others. She has researched and worked with companies in various sectors, including banking, mobile networks, affiliate networks, consumer goods and wearable technologies. 